\title{
Synthesis of mullite powders using precipitated silica and tetraethoxy silane and aluminium-formate as precursor materials in aqueous medium
}

\author{
N N GHOSH and P PRAMANIK* \\ Department of Chemistry, Indian Institute of Technology, Kharagpur 721 302, India \\ MS received 23 December 1996; revised 11 February 1997
}

\begin{abstract}
Mullite $\left(3 \mathrm{Al}_{2} \mathrm{O}_{3}-2 \mathrm{SiO}_{2}\right)$ powder was prepared by using an aqueous sol-gel method where aluminium formate and tetraethoxy silane (TEOS) and precipitated silica were used as the precursor compounds and water was used as reaction medium instead of the conventionally used solvent alcohol. The gels were calcined at $1000^{\circ} \mathrm{C}, 1200^{\circ} \mathrm{C}$ and $1300^{\circ} \mathrm{C}$ for $1 \mathrm{~h}$ and characterized by $\mathrm{X}$-ray powder diffraction, infrared spectroscopy, differential thermal analysis, thermogravimetry analysis and transmission electron microscopy. This method is shown to provide homogeneous, reactive amorphous powder at comparatively low temperatures.
\end{abstract}

Keywords. Mullite; sol-gel; XRD.

\section{Introduction}

Mullite $\left(3 \mathrm{Al}_{2} \mathrm{O}_{3}-2 \mathrm{SiO}_{2}\right)$ has a unique combination of properties such as good high temperature strength and creep resistance, chemical inertness and thermal stability, low thermal expansion coefficient and low thermal conductivity and low dielectric constant. As a result, mullite and mullite-based ceramics are promising candidate materials for use as high temperature structural components, refractories, ceramic substrates in multilayer microelectronic packages and window materials in the midinfrared range (Lathabai et al 1996).

In order to increase both purity and homogeneity of mullite samples a lot of work concerning sol-gel routes using different precursors and/or processes have been reported (Yoldas 1980; Hoffman et al 1984; Sacks et al 1990; Aksay et al 1991; Somiya and Hirata 1991). But the rate of hydrolysis of silicon alkoxides are very slow as compared with that of Al-alkoxides. Different rates of hydrolysis of the alkoxides may result in chemical inhomogeneity in the product or higher crystallization temperatures and undesired crystalline phases.

As the metal-alkoxides used in all alkoxide sol-gel routes are costly and their laboratory preparations are complex in nature, we have initiated to simplify the all-alkoxide sol-gel route (Pramanik and Saha 1990; Saha and Pramanik 1993, 1994, 1995; Ghosh and Pramanik 1996). The objective of our work is the development of an efficient and low-cost processing sol-gel route. We have modified the all-alkoxide sol-gel technique by using metal formates instead of metal alkoxides and water as the reaction medium instead of commonly used solvent alcohol. As water is used as reaction medium the method was termed as 'aqueous sol-gel' method.

In the present work, mullite powder was synthesized by using the aqueous sol-gel method where aluminium formate and tetraethoxy silane (TEOS) and precipitated silica were used as precursor compounds and water as reaction medium.

*Author for correspondence 


\section{Experimental}

Freshly precipitated aluminium hydroxide was prepared by adding ammonium hydroxide to aqueous solution of aluminium nonahydrate (BDH Chemicals, India). After filtering and washing with distilled water this was then reacted with aqueous formic acid solution $(50 \% \mathrm{wt} / \mathrm{v})$ to give aluminium formate solution $(50 \% \mathrm{wt} / \mathrm{v})$. Aluminium formate solution containing the required amount of aluminium ion was then added to TEOS keeping Al:Si ratio $3: 1$. At the beginning of mixing TEOS and aqueous aluminium formate solution was immiscible. A homogeneous solution was obtained after about $30 \mathrm{~min}$ of hydrolysis of TEOS under rapid stirring using a magnetic stirrer. Similarly a gel was prepared by mixing a suspension of precipitated silica in aqueous medium $(50 \% \mathrm{wt} / \mathrm{v})$ which was free from $\mathrm{Na}^{+}$ions or any other cations and aqueous aluminium formate solution $(50 \% \mathrm{wt} / \mathrm{v})(\mathrm{Si}$ : Al ratio $3: 1)$.

The gels formed after $7 \mathrm{~h}$ which were then dried over a water bath for $24 \mathrm{~h}$ and then ground to powders. The dried gel powders were then calcined at $1100^{\circ} \mathrm{C}, 1200^{\circ} \mathrm{C}$ and $1300^{\circ} \mathrm{C}$ for $1 \mathrm{~h}$.

The crystallined phases were identified by X-ray (XRD) using a Philips X-ray powder diffractometer PW 1840 and $\mathrm{CuK}_{\alpha}$ radiation. Infrared (IR) spectras were recorded using a Perkin Elmer 883 IR spectrophotometer, for IR spectras samples were prepared using the $\mathrm{KBr}$ pellet method. Thermogravimetric analysis (TGA) and differential thermal analysis (DTA) runs were carried out at a heating rate of $10^{\circ} \mathrm{Cmin}^{-1}$ in air using a Shimadzu thermal analyser DT 40. Electron microscopic examination of powder were carried out by transmission electron microscope (TEM) using Philips CM 12. The samples for TEM were prepared by depositing the powders on a carbon film.

\section{Results and discussion}

The TGA of dried gel powders exhibit two-step weight loss. The total weight loss in the dried gel was about $68 \mathrm{wt} \%$. Constant weight was observed after $550^{\circ} \mathrm{C}$. The DTA endothermic peak $\left(125^{\circ} \mathrm{C}\right)$ was due to the removal of water from gel and the exothermic peak at $300^{\circ} \mathrm{C}$ was attributed to decomposition and oxidation of formate salts.

$\mathrm{X}$-ray powder diffraction patterns of the samples calcined at different temperatures are shown in figure 1 . The gel powder obtained from TEOS and aluminium formate was amorphous to $\mathrm{X}$-ray until heated up to $1100^{\circ} \mathrm{C}$ for $1 \mathrm{~h}$. The X-ray diffraction peaks corresponding to mullite phase were observed when the gel powder was calcined at $1200^{\circ} \mathrm{C}$ and $1300^{\circ} \mathrm{C}$ for $1 \mathrm{~h}$. The gel obtained from precipitated silica and aluminium formate showed characteristic XRD peaks of mullite when calcined at $1200^{\circ} \mathrm{C}$ for $1 \mathrm{~h}$. The XRD peaks increased in intensity with subsequent heat treatments. This indicates the growth of crystallinity in the powders with the increase of calcination temperatures. The particle sizes were calculated by X-ray peak broadening method and observed that the average particle size of the powders were $85 \mathrm{~nm}-115 \mathrm{~nm}$.

In the gel powder dried at $100^{\circ} \mathrm{C}$ obtained from TEOS and aluminium formate principal absorption band of formate group at $1380 \mathrm{~cm}^{-1}$ was observed. The disappearance of IR band at $1380 \mathrm{~cm}^{-1}$ due to calcination at higher temperatures confirmed that the formate group was no longer in the system when the calcination temperatures were $1100^{\circ} \mathrm{C}, 1200^{\circ} \mathrm{C}$ and $1300^{\circ} \mathrm{C}$. The IR spectra of the sample calcined at $1200^{\circ} \mathrm{C}$ or higher temperature for $1 \mathrm{~h}$ showed the characteristic bands of mullite 


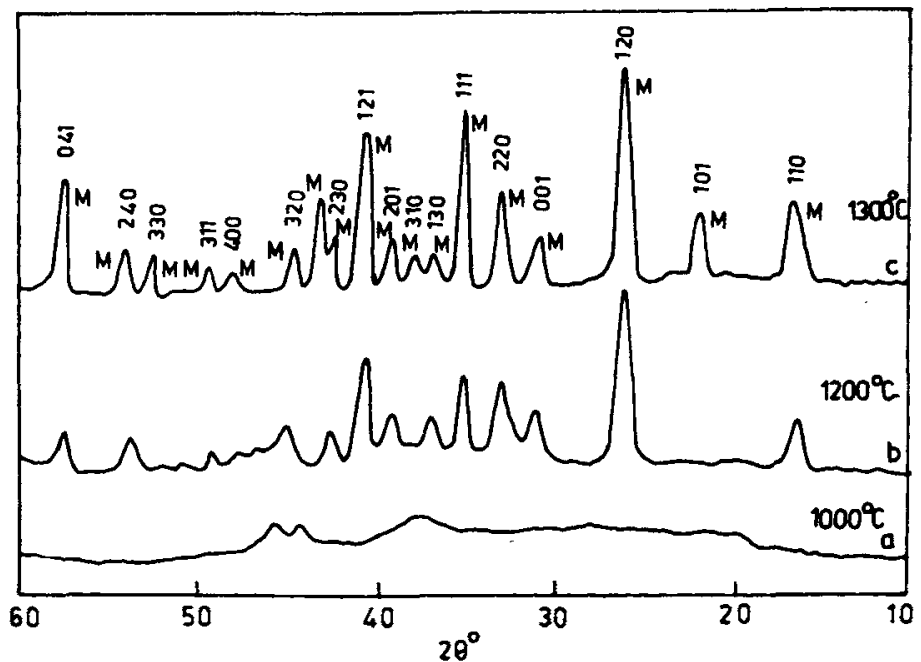

Figure 1. X-ray diffraction patterns of mullite samples calcined at different temperatures.

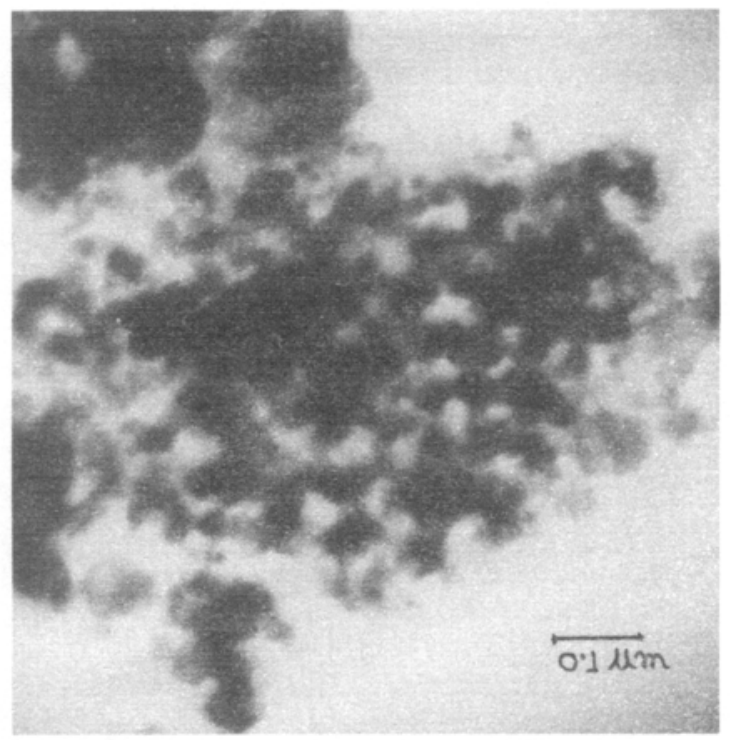

Figure 2. TEM micrograph of mullite powder obtained from TEOS and Al-formate (calcined at $1300^{\circ} \mathrm{C}$ ).

(Gadsden 1975) at $1175 \mathrm{~cm}^{-1}, 1125 \mathrm{~cm}^{-1}, 814 \mathrm{~cm}^{-1}, 750 \mathrm{~cm}^{-1}, 560 \mathrm{~cm}^{-1}$ and $450 \mathrm{~cm}^{-1}$. Similar types of observations were found for the gel and calcined powders obtained from precipitated silica and aluminium formate.

From TEM it was observed that the average particle size of the powders were in nanometer scale $(100 \mathrm{~nm}-125 \mathrm{~nm}$ ) (figure 2). The particle sizes were increased with the increase of calcination temperatures. 


\section{Conclusion}

Nanosized mullite powders were prepared by aqueous sol-gel method using aluminium formate and TEOS or precipitated silica as starting materials and water as reaction medium. The preparation of mullite from $\mathrm{Al}$ formate and fumed silica posed a difficulty for obtaining the homogeneous gel due to fumed silica to be sedimented. The precipitated silica easily forms colloidal solution with $\mathrm{Al}^{+3}$ in presence of weak acids and forms a homogeneous gel. This aqueous sol-gel method has proved to be a convenient method for producing homogeneous reactive, amorphous powders at comparatively low temperature and has the novelty for its simplicity and cost effectiveness.

Synthesis and characterization of different silicate systems such as (i) $\mathrm{ZrO}_{2}-\mathrm{SiO}_{2}$, (ii) $\mathrm{BaO}-\mathrm{SiO}_{2}$, (iii) $2 \mathrm{Al}_{2} \mathrm{O}_{3}-\mathrm{SiO}_{2}$, (iv) $\mathrm{Li}_{2} \mathrm{O}-\mathrm{Al}_{2} \mathrm{O}_{3}-2 \mathrm{SiO}_{2}$, (v) $\mathrm{Li}_{2} \mathrm{O}-\mathrm{Al}_{2} \mathrm{O}_{3}-4 \mathrm{SiO}_{2}$, (vi) $2 \mathrm{MgO}-2 \mathrm{Al}_{2} \mathrm{O}_{3}-5 \mathrm{SiO}_{2}$ etc using precipitated silica and metal formate solutions are under progress.

\section{References}

Aksay I A, Dabbs D M and Sarikaya M 1991 J. Am. Ceram. Soc. 742343

Gadsden J A 1975 Infrared spectra of minerals and related inorganic compounds (London: Butterworth)

Ghosh N N and Pramanik P 1996 Br. Ceram. Trans. 95209

Hoffman D W, Roy R and Komerneni S 1984 J. Am. Ceram. Soc. 67468

Lathabai S, Hay D G, Wagner F and Claussen N 1996 J. Am. Ceram. Soc. 79248

Pramanik P and Saha S K 1990 J. Mater. Sci. Lett. 11311

Sacks M D, Lee H W and Pask J A 1990 Ceramic transactions (Westerville, OH: American Ceramic Society) Vol. 6

Saha S K and Pramanik P 1993 J. Non-Cryst. Solids 15931

Saha S K and Pramanik P 1994 J. Mater. Sci. 293425

Saha S K and Pramanik P 1995 J. Mater. Sci. 302858

Somiya S and Hirata Y 1991 Ceram. Bull. 701624

Yoldas B E 1980 Am. Ceram. Soc. Bull. 59479 